\title{
Drug interactions in the pharmacotherapy of patients included in primary care comprehensive medication management services
}

\author{
Hágabo Mathyell SILVA ${ }^{1}$, Djenane RAMALHO-DE-OLIVEIRA ${ }^{1}$ (D), Ursula de Morais MARTINS ${ }^{1}$ (D) , Yone de Almeida NASCIMENTO ${ }^{\text {(D) }}$ \\ Adriano Moreira REIS $^{1}$ iD, Aline de Assis SANTOS $^{1}$ iD, Mariana Gonzaga do NASCIMENTO ${ }^{1}$ (D) \\ ${ }^{1}$ Universidade Federal de Minas Gerais; ${ }^{2}$ Centro Universitário Newton Paiva \\ Corresponding author: Silva HM, hagaboms@gmail.com
}

Submitted: 07-12-2020 Resubmitted: 11-05-2021 Accepted: 12-05-2021

Peer review: blind reviewers

\begin{abstract}
Objective: A drug interaction (DI) is the clinical event in which the effect or action of one drug is modified by the presence of another. Because of potential harms and low consistency of available information, it is critical to assess the clinical relevance of DI. This study aimed to identify and evaluate the clinical consequences of DI in the pharmacotherapy of patients followed in a primary care Comprehensive Medication Management (CMM) services. Methods: This observational cross-sectional study was based on the analysis of the CMM records all the patients that used at least two medications and attended to at least three CMM consultations from August 2015 to March $2016(n=88)$. Potential DI were identified among the medications used in the initial consultation of CMM using Micromedex ${ }^{\circledR}$ Drug-Reax ${ }^{\circledR}$ software. The DI were classified as "monitorable" (when its clinical consequences could be monitored by effectiveness or safety paremeters) or non-monitorable, and their clinical consequences were evaluated by analysis of CMM records. Results: Among the studied population $95.5 \%$ of the patients had at least one potential DI in their pharmacotherapy, totaling 493 potential DI. Of all the potential DIs identified, $90.9 \%$ were monitorable, and the majority of these monitorable DI presented no clinical consequences (62.7\%). For $63.9 \%$ of the DI with clinical impact, the pharmacist adopted direct or indirect measures that would favor the resolution or reduction of the clinical impact of DIs. Conclusion: The CMM service facilitates the management of DIs since its decision-making method calls for monitoring of the effectiveness and safety parameters, individualizing the management of DIs according to the patient's needs and their clinical consequences.
\end{abstract}

Keywords: medication therapy management; drug interactions; primary health care.

\section{Interações medicamentosas na farmacoterapia de pacientes incluídos em serviços de gerenciamento da terapia medicamentosa na atenção primária}

\begin{abstract}
Resumo
Objetivo: Interação medicamentosa (IM) é o evento clínico no qual o efeito ou ação de um medicamento é modificado pela presença de outro. Por causa dos danos potenciais e da baixa consistência das informações disponíveis, é fundamental avaliar a relevância clínica da IM. O objetivo deste estudo foi identificar e avaliar as consequências clínicas da IM na farmacoterapia de pacientes acompanhados em serviços de Gerenciamento da Terapia Medicamentosa (GTM) na atenção primária. Métodos: Este estudo observacional do tipo transversal baseou-se na análise dos prontuários do GTM de todos os pacientes que usaram pelo menos dois medicamentos e compareceram a pelo menos três consultas do CMM no período de agosto de 2015 a março de 2016 ( $n=88$ ). Potenciais IM foram identificados entre os medicamentos utilizados na consulta inicial do GTM por meio do software Micromedex ${ }^{\circledR}$ Drug-Reax $^{\circledR}$. As IM foram classificadas como "monitoráveis" (quando suas consequências clínicas pudessem ser monitoradas por parâmetros de eficácia ou segurança) ou não monitoráveis, e suas consequências clínicas foram avaliadas pela análise dos registros do GTM. Resultados: Na população estudada 95,5\% dos pacientes apresentaram pelo menos um IM potencial em sua farmacoterapia, totalizando 493 IM potencial. De todas as IMs potenciais identificados, 90,9\% eram monitoráveis, e a maioria dessas IMs monitoráveis não apresentava consequências clínicas (62,7\%). Para 63,9\% das IM com impacto clínico, o farmacêutico adotou medidas diretas ou indiretas que favoreceriam a resolução ou redução do impacto clínico das IM. Conclusão: O serviço de GTM facilita o gerenciamento das IMs, pois seu método de tomada de decisão evolui no monitoramento dos parâmetros de eficácia e segurança, individualizando o manejo das IMs de acordo com as necessidades do paciente e suas consequências clínicas.
\end{abstract}

Palavras-chave: conduta do tratamento medicamentoso; interações medicamentosas; atenção primária à saúde. 


\section{Introduction}

Drug interactions (DIs) are clinical events in which the action or effects of a drug are modified by the presence of another drug, food, drink or some environmental chemical agent. Medications used by a patient may act independently or interact with each other. ${ }^{1,2}$ These interactions can be beneficial, harmful or without any consequence to the health of individuals. The outcome resulting from a DI will depend not only on the drugs involved, but also on the characteristics of individuals and their clinical state. ${ }^{1,3}$

Despite difficulties in elucidating all the mechanisms involving DIs, they can be classified by the results of preclinical and clinical studies. Pharmacokinetic DIs occur when one drug modifies the kinetics of another drug in the body. Thus, interference may occur in the process of absorption, distribution, biotransformation or excretion of the subject drug. ${ }^{3-5}$ Pharmacodynamic interactions can be divided into action DIs and effect DIs. The former ones are those in which the action of a drug is influenced by the presence of another drug at the site of biological activity (receptors or enzymes) or in the molecular structures following activation. . $^{3,4,6}$ However, effect Dls occur from drugs with pharmacological pathways and different binding sites, but which have synergistic or antagonistic effects. ${ }^{6}$

Different approaches can be used to prevent or circumvent the occurrence of DIs. Most them use the medical prescription as an instrument of identification and isolated evaluation of the interaction. If, on one hand, these methods are more practical and require less time to identify potential drug interactions (PDIs); on the other hand, the focus on prescription usually does not provide information about the patient's clinical condition and, consequently, does not allow the assessment of the clinical impact of the DIs on the patient's treatment. The computerized DI alert systems are a widely used tool in the health services, but most of them also do not provide information contextualized with the clinical condition of the patient, which generates alert fatigue, and lead to clinicians ignoring them in frequencies thar commonly exceed $90 \%$. 7,8

Therefore, a more contextualized and holistic approach can be carried out in a Comprehensive Medication Management (CMM) service, in which the pharmacist uses the theoretical framework of Pharmaceutical Care to optimize pharmacotherapeutic clinical outcomes. In this service, the professional is responsible for identifying, preventing and resolving drug therapy problems (DTP). ${ }^{9-11}$ There are several probable causes for a DTP, and DI, as a group, comprise one of them. The decision-making method used in this practice recommends that professionals evaluate sequentially whether the medications are indicated, effective and safe, and if the patient can use them (adherence). ${ }^{11}$ Thus, DI should be considered only with the identification of compromised effectiveness (the patient may use two or more drugs that interact to reduce the effectiveness of one of them) or safety (drug interaction may cause an adverse drug reaction - ADR; or increase the plasma concentrations of a drug - high dose). ${ }^{12}$

Some studies have already identified a high proportion of potential DI. However, to the best of our knowledge, no study has evaluated the prevalence and clinical consequences of DI among patients included in CMM services to date. In this perspective, this study aimed to describe DI found in the pharmacotherapy of patients followed in primary care CMM service, as well as their consequences and relevance within the decision-making process proposed by the Pharmacotherapy Workup (PW).

\section{Methods}

This observational cross-sectional study is part of a study on the assessment of the clinical impact of the CMM service provided in 11 primary care units of the Brazilian public health system of the city of Betim, located in the metropolitan region of Belo Horizonte (Minas Gerais). The service was intended for patients who did not achieve the therapeutic goals, and the present study evaluated CMM consultations performed from August 2015 to March 2016 with a total of 280 patients. Among those, all patients that had participated in at least three CMM consultations and used at least two drugs in their initial evaluation constituted the 88 patient's population of our study. This selection strategy allowed the exclusion of patients with a lower number of pharmaceutical consultation and who had no clinical/laboratory results, which could compromise the evaluation of the clinical consequences of the DI.

All data was retrospectively collected from the computerized medical records of the CMM service. The following variables were collected: gender, age, schooling, health problems and medications used. Medications used were classified according to the Anatomical Therapeutic Chemical classification system (ATC). ${ }^{13}$

Potential DI were identified in the list of used medications documented for the initial CMM evaluation. For such, Micromedex ${ }^{\circledR}$ Drug-Reax ${ }^{\circledR}$ software was used; it has specificity and sensitivity for the identification of interactions for scientific investigation and use in clinical practice at hospital and primary care levels. ${ }^{14-16}$ All potential DI were classified by severity (contraindicated, major, moderate, minor and unknown) and by the level of scientific documentation (excellent, good, fair and unknown) adopting the specifications of the Drug-Reax ${ }^{\circledR}$ software.

According to the description of the clinical consequences, available in the Drug-Reax ${ }^{\circledR}$ software, potential DI were classified as: a) monitorable, when their undesirable clinical consequences could be monitored through laboratory or clinical parameters evaluated in primary care; or b) non-monitorable, when DI could not have their undesirable clinical consequences monitored in this way. This classification was performed independently by two clinical pharmacists with vast experience on CMM and other pharmaceutical services provision, but that did not provide CMM on the studied site. In case of disagreement between the pharmacists on any classification, it was discussed until a consensus was reached.

These two pharmacists also evaluated all CMM records in order to differentiate the monitorable $\mathrm{DI}$ according to the actual occurrence of clinical consequences. In this context, monitorable DI with clinical consequences were identified as those that generated an undesirable impact on the clinical/laboratory results documented in the CMM records (eg. low fasting blood glucose levels for DI that cause hypoglycemia; or high blood pressure for DI that reduce antihypertensive effectiveness). On the other hand, monitorable DI without clinical consequences were identified as those that generate no undesirable impact. However, for some monitorable $\mathrm{DI}$, it was not possible to evaluate their clinical consequences due to the absence of clinical/laboratory results.

The type of adverse clinical consequence associated with a monitorable or non-monitorable DI and the conduct of the CMM provider in the face of a DI were evaluated. An assessment was 
also made regarding whether the pharmacist identified any DTP in the face of DI.

In the present study, DI involving at least one medication classified by clinical pharmacists as "unnecessary" (DTP 1 according to the Pharmacotherapy Workup method) were also identified. That is, the patient had no medical condition that would justify the use of at a medication involved in the DI.

A descriptive analysis of the data was performed, which established the absolute and relative frequencies for the categorical variables and the central tendency (mean and standard deviation, or median), minimum and maximum for the quantitative variables.

This study is a part of the project "Clinical, economic, humanistic, cultural and educational results in the Drug Therapy Management in the Unified Health System", approved by the Research Ethics Committee of Federal University of Minas Gerais on May 28 , 2014, under CAAE - 25780314.4.0000.5149.

\section{Results}

The studied population consisted mainly of women ( $n=53 ; 60.2 \%)$ and had a median of 65 years. The total number of medications used per patient at the first CMM evaluation ranged from 2 to 14 medications (median $=7$ ), and most patients used five or more medications $(n=72 ; 81.8 \%)$, which increases the exposure to DI (Table 1).

Table 1. Characteristics of the patients included in the study $(\mathrm{n}=$ 88). Betim, Minas Gerais, Brazil. 2015-2016.

\begin{tabular}{lc}
\hline Characteristics & $\mathbf{n}(\%)$ \\
\hline Sex & \\
Male & $35(39.8)$ \\
Female & $53(60.2)$ \\
Age (years completed) & \\
$\leq 49$ & $10(11.4)$ \\
$50-59$ & $19(21.6)$ \\
$60-69$ & $27(30.7)$ \\
$\geq 70$ & $32(36.4)$ \\
Number of health problems in the initial assessment \\
$1-3$ & $23(26.1)$ \\
$4-5$ & $36(40.9)$ \\
$\geq 6$ & $29(33.0)$ \\
Number of medications in the initial assessment & \\
$2-4$ & $16(18.2)$ \\
$5-9$ & $54(61.4)$ \\
$\geq 10$ & $18(20.5)$ \\
Schooling (years) & \\
0 & $20(22.7)$ \\
$1-4$ & $44(50.0)$ \\
$\geq 5$ & $15(17.0)$ \\
Uninformed & $09(10.2)$ \\
\hline
\end{tabular}

The most commonly used drugs were aspirin [B01AC06] ( $n=52$; used by $10.1 \%$ of the patients), simvastatin [C10AA01] ( $n=52$; 10.1\%), metformin [A10BA02] $(n=38 ; 7.4 \%)$ and enalapril [CO9AA02] ( $n=37,7.2 \%)$. The most prevalent health problems among the patients were those already expected in a primary health care service: hypertension ( $n=76 ; 86.4 \%)$, type 2 diabetes mellitus ( $n=51 ; 60.0 \%)$ and dyslipidemia ( $n=44 ; 50.0 \%)$. The number of health problems per patient ranged from 1 to 9 (median $=5)$.

\section{Potential Drug Interactions}

We observed that 84 patients (95.5\%) had at least one potential $\mathrm{DI}$ identified among the medication used in their initial CMM evaluation, and a total number of 493 potential DI were found (mean $=5.6 \pm 4,3 \mathrm{PDI} /$ patient; minimum $=0 ;$ maximum=22). In total, 163 different types of potential DI were detected, being "NPH insulin + metformin" ( $n=25 ; 5.1 \%)$ the most frequent one. Potential DI involving "aspirin + enalapril", "aspirin + NPH insulin" and "amlodipine + simvastatin" were also frequent $(n=24 ; 4.9 \%$ for each interaction).

Regarding their classification of severity and relevance, most of the potential DI detected were from the group of interactions with 'moderate severity' $(n=331 ; 67.1 \%)$ or 'major' ( $n=137$; $27.8 \%$ ). According to their documentation level, most of the potential DI had good scientific documentation ( $n=220 ; 44.6 \%)$.

Considering only the potential DIs classified as 'major' or 'contraindicated', and with 'good' or 'excellent' scientific documentation, 141 PDIs were identified, divided into 57 different DI types. After this selection, the most frequent PDIs were: "amlodipine + simvastatin" $(n=23 ; 16.3 \%)$, "aspirin + hydrochlorothiazide" ( $n=19 ; 13.5 \%)$ and "aspirin + furosemide" $(n=15 ; 10.6 \%)$.

\section{Monitorable Drug Interactions}

We found that, of the total potential DIs identified $(n=493)$, the majority was monitorable ( $n=448 ; 90.9 \%)$. Then, we observed that, of those, the majority had no clinical consequences identified $(n=281 ; 62.7 \%$ of the monitorable DI). For only $10,0 \%$ of the monitorable $\mathrm{DI}(\mathrm{n}=45)$, however, it was not possible to evaluate their clinical outcomes due to the lack of monitoring parameters documentation (Figure 1).

On the other hand, few undesirable clinical consequences were identified for $27,2 \%$ of the monitorable DI ( $n=122)$, and the most frequent DI of these DI were: "amlodipine + simvastatin" $(n=10)$, "NPH insulin + metformin" ( $n=7)$ and "aspirin + hydrochlorothiazide" $(n=5)$. The most frequent undesirable clinical consequences associated with these monitorable DI were hypoglycemia $(n=45$; $36.9 \%)$ and hyperglycemia ( $n=15,12.3 \%)$ (Table 2).

Table 2. Frequency of adverse clinical consequences associated to monitorable drug interactions identified in the pharmacotherapy of patients followed in the CMM service. Betim, Minas Gerais, Brazil. 2015-2016.

\begin{tabular}{ll}
\hline Clinical Consequence & $\mathbf{n}(\%)$ \\
\hline Hypoglycemia & $45(36.9)$ \\
Hyperglycemia & $15(12.3)$ \\
Kidney disfunction & $12(9.8)$ \\
Myopathy & $11(9.0)$ \\
Hypotension & $10(8.2)$ \\
Bradycardia & $8(6.6)$ \\
Benzodiazepine intoxication & $5(4.0)$ \\
Others & $16(13.2)$ \\
TOTAL & $122(100.0)$ \\
\hline
\end{tabular}


Figure 1. Drug interactions identified in the pharmacotherapy of patients followed in the CMM service. Betim, Minas Gerais, Brazil. $2015-2016$.

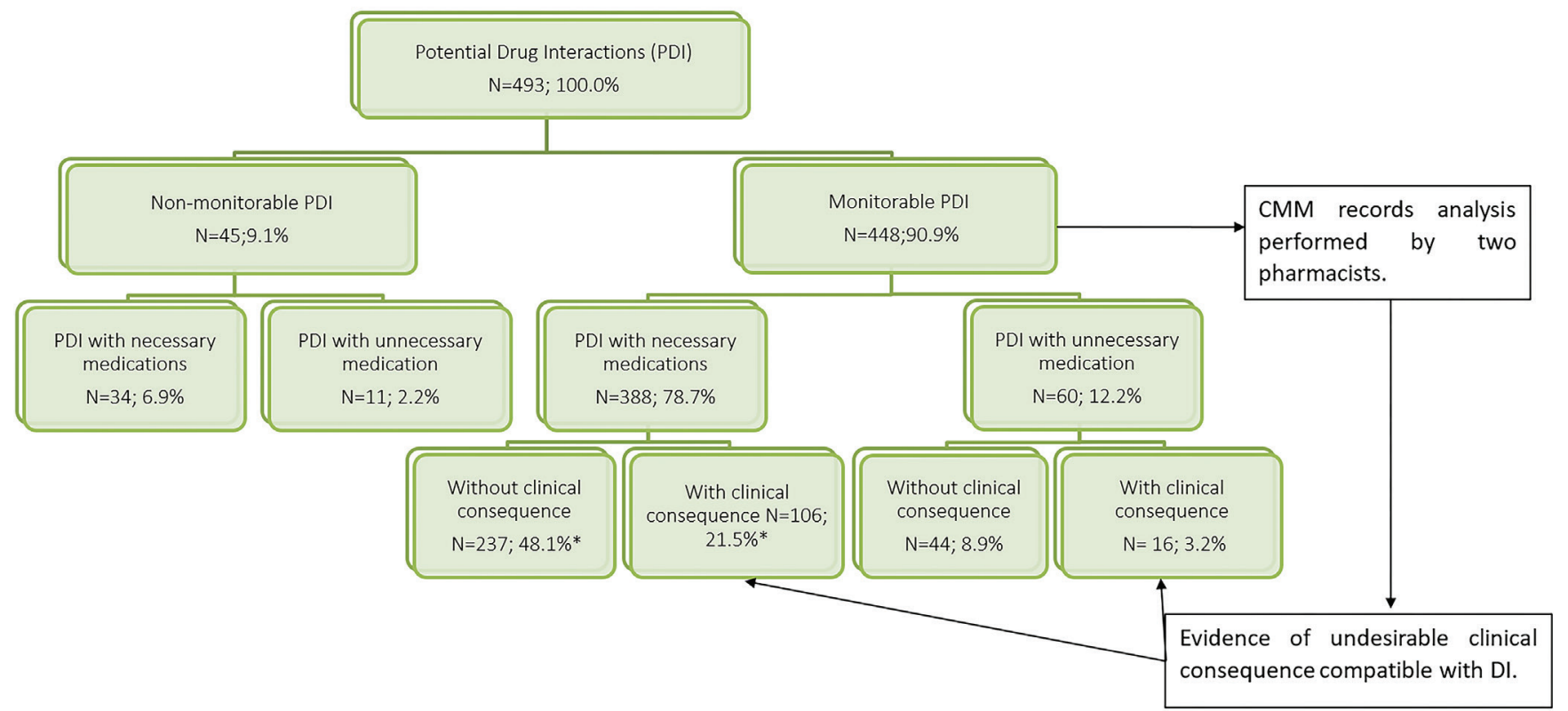

*Aditional 45 PDIs (9.1\%) with necessary medications did not present clinical consequences documented in CMM records; ** DI - drug interaction; PDIs - potential drug interactions; $\mathrm{CMM}$ - comprehensive medication management

It was observed that, for 78 of the monitorable and clinically manifested DI (63.9\%), the pharmacist identified a DTP and took direct or indirect measures that favored the resolution of the interaction or minimized its clinical impact. The most frequent intervention performed concerning the identified clinical outcome was the suggestion of a contraindicated drug suspension ( $n=24 ; 30.0 \%)$, followed by a reduced drug dose ( $n=17 ; 21.8 \%)$, change of drug due to adverse reaction or ineffectiveness ( $n=15,19.2 \%)$, dose increase $(n=12,15.4 \%)$, and withdrawal of the non-effective drug ( $n=10,12.8 \%)$.

On the other hand, for another 10 monitorable and clinically manifested DI (8.2\%), the pharmacist identified a DTP that led to the adoption of a conduct that could enhance the clinical impact of a DI. For the other $34 \mathrm{DI}(27.9 \%)$, the pharmacist did not identify any DTP and no conduct was adopted regarding the DI.

\section{Non-monitorable Drug Interactions}

We observed that, of the 493 PDIs found, 45 (9.1\%) were classified as non-monitorable. These could be grouped into thirty types of $\mathrm{DI}$, and the most frequent were "aspirin + ibuprofen" ( $\mathrm{n}=4 ; 7.7 \%)$ and "aspirin + fluoxetine" ( $n=3,5.8 \%)$.

The most frequent potential adverse clinical consequences expected for the non-monitorable DI were bleeding (48.0\%) and reduced effectiveness of CV disorder prophylaxis (31.0\%). The "aspirin + ibuprofen" interaction was the most frequent potential cause.

Of the total non-monitorable PDIs ( $n=45), 11(24.4 \%)$ involved at least one drug that the pharmacist identified as contraindicated (safety DTP); and another 5 (11.1\%) involved at least one drug which the patient was not using (involved in non-adherence DTP). Among the 29 remaining non-monitorable PDIs, it was observed that 18 were not targeted by the pharmacist; another 9 were adequately addressed by the practitioner with an intervention that solved the potential problem involved in the DI. For the last non-monitorable $\mathrm{DI}$, the pharmacist increasing the dose of one of the medications involved in the $\mathrm{DI}(\mathrm{n}=1)$ or ignored the presence of the $\mathrm{DI}(\mathrm{n}=1)$.

\section{Unnecessary drugs}

Of the total potential DIs identified ( $n=493), 71(14.4 \%)$ involved at least one unnecessary drug (involved in a DTP 1 identified at the initial CMM assessment). The potential DI with this particularity were found for almost half of the patients (45.2\%). Aspirin was the drug most frequently involved in a potential DI and DTP1 simultaneously ( $n=13 ; 16.9 \%)$. In addition, it was observed that most DI involving unnecessary drugs were monitorable $(n=60$; $12.2 \%)$ and $16(3.2 \%)$ of these had clinical manifestations.

\section{Discussion}

The high prevalence of older patients and polypharmacy (use of five or more medications ${ }^{17}$ ) in this study is in line with other studies that indicate that this group of patients frequently present DTPs in their pharmacotherapy, and, consequently, can benefit considerably the CMM service. ${ }^{18,19}$ On the other hand, the older age detected causes concern, since the mean of potential DI identified was high (95.5\%), and DI tend pose more threats to this population due to the considerable pharmacokinetic and pharmacodynamic changes caused by the aging process that can potentialize their adverse clinical consequences. ${ }^{20-22}$ The mean of DI encountered (mean= $5.9 \mathrm{DI} /$ patient) was, however, similar to that found in other studies ${ }^{22,23}$, and involved mainly the most commonly used drugs among the study's patients, as expected. 
Most of the potential DI were of "moderate severity" or "major" (94.9\%) and with "good" scientific documentation (44.6\%), and the most frequent DI was "NPH insulin + metformin" $(n=25$ $5.1 \%)$. Many studies only report major DI, and, if this was the case in the present study, the most frequent potential DI would be "amlodipine + simvastatin" $(n=23 ; 16.3 \%){ }^{21,24}$ However, it is important to point out that, in clinical practice, one should not consider only DI classified as "major", because those considered moderate can also cause serious damage, especially to more vulnerable patients, such as the older patients. ${ }^{3,21}$ In this sense, the most frequent potential DI in this study ( $\mathrm{NPH}$ insulin + metformin), despite being classified as "moderate" in severity, could contribute to serious hypoglycemia among the majority of older patients identified in the present study. ${ }^{25}$

According to the classification of the $\mathrm{DI}$ in terms of their monitorability, it was possible to verify that most DI were classified as monitorable (90.9\%), but few were associated with a detectable clinical consequence (27\%), very similar to that found by Dumbreck et al. ${ }^{24}$ These results reveal that the pharmacist could and should easily use clinical parameters to determine the existence of a DI whenever possible, since the identification of a potential DI in the pharmacotherapy does not necessarily reflect a clinical alteration. ${ }^{2,26}$ That is, when it comes to a monitorable DI, continuous attention to the parameters of effectiveness and safety of each medication can go a longer way than the identification of all DI and their communication to the health team.

On the other hand, it is necessary to consider that other causes may have altered the parameters of those monitorable DI that were actually associated with a clinical consequence, such as low dose, high dose and inappropriate frequency. Cipolle et al. (2012) found that DI configurate only the fifth most frequent cause of low and high doses, in addition to being only the third most frequent cause of ADR. ${ }^{12}$ The presence of multiple health problems, found in the present study (mean=4,6), can also contribute to and exacerbate those clinical consequences. But this only reinforces the knowledge that DI investigation and causality evaluation is usually tricky and should be cautious and properly contextualized with the patient's clinical status.

Although non-monitorable DI were not the most frequent, this group of DI demands greater attention by the pharmacists, since there are no clinical parameters and laboratory readily available in primary care that allows their adequate monitoring. In addition, the multiple pairs of drugs associated with this type of DI offer a challenge for the clinician and reinforces the importance of having a reliable database for continuous consultation.

The most frequent potential adverse clinical consequences expected for the non-monitorable DI was bleeding (48.0\%). Although it is possible to monitor bleeding through minor signs (e.g., petechiae, bruising, bleeding gums, and so forth) and laboratory tests (e.g., PT and APTT), patients can develop severe bleeding (intracranial, gastrointestinal) that is not preceded by minor bleeding. ${ }^{27,28}$ This is especially true in older patients, which were a majority in the present study. ${ }^{17} \mathrm{DI}$ that could cause bleeding occurred mainly in the concomitant use of an NSAID and an antidepressant ( $n=15 ; 35.71 \%)$, pointing out to the necessity of choosing alternative medication that do not involve those $\mathrm{DI}$, and also to reevaluate the necessity of NSAID use, including prophylactic aspirin.

Reduced effectiveness of CV disorder prophylaxis was the second most frequent non-monitorable potential outcome (31.0\%), and the "aspirin + ibuprofen" interaction was the most frequent potential cause. Since it is not possible to monitor the effectiveness of medications with this protective action, it is essential to adopt measures in order to minimize the clinical impact of these interactions, including the reduction of NSAID use..$^{29-32}$

A limitation of the present study was the fact that drug dosages were not taken into consideration to differentiate the propensity of DI clinical consequences. For instance, it is well known that the DI involving simvastatin are more relevant with doses higher than $20 \mathrm{mg}$. This was decision made according to the software used in the analyse (Micromedex ${ }^{\circledR}$ ) that does not point out this particularity. On the other hand, it is important to discuss that drug interactions in complex patients, using multiple drugs may be mutually potentiated; for instance, a patient can use a CYP inhibitor that enhances the clinical results of another drug interaction that involves a CYP substrate. This possibility was not explored in the present study, and should be considered by other researchers, as well as evaluating drug dosages.

Another limitation of the present study was the impossibility of assessing the clinical relevance of some drug interactions due to the lack of medical records. This lack of registration can be explained by the fact that the services studied are inserted in the Brazilian public health system, where resources are limited, which made it difficult to perform laboratory tests. In addition, CMM is a service that is not widespread in Brazil and as a consequence, the clinical pharmacists who provided the service were new at the time of the study, although they received extensive theoretical and practical training in pharmaceutical care with the support of the University.

In the present study, within the care process, the pharmacist identified and intervened directly or indirectly in $55.0 \%$ of the non-monitorable Dls. This number is significant, given the difficulties in identifying and addressing interactions of this nature. On the other hand, we noticed that the adoption of no attitude to eliminate or reduce the impact of the DI was observed for a considerable part of the non-monitorable DIs $(24.0 \%)$. The pharmacotherapy workup method proposes that all clinical and laboratory parameters should be considered for the correct evaluation of effectiveness and safety. ${ }^{9-11}$ However, when it comes to non-monitorable PDIs, the lack of such parameters can lead to the professional's forgetfulness since these are the main alerts of the existence of this group of problems. This significant fraction indicates that it is still necessary to align the conduct of the professionals working in the CMM services to identify the nonmonitorable DIs and to design strategies to circumvent them. It is also worth highlighting the lack of a computer or internet access in the studied CMM service and the frequent performance of CMM consultation in the patient's home, which may reduce the access of the professional to the potential DI verification software.

A significant percentage of the potential DI involved at least one unnecessary drug $(14,4 \%)$. This scenario reveals that, after discontinuing unnecessary drugs, a considerable part of the potential DI would cease to exist and, therefore taking actions towards managing these $\mathrm{DI}$ would also become unnecessary. In this sense, the logical and sequential decision-making method proposed by the pharmacotherapy workup allows greater organization of reasoning, and minimizes the chances of overestimating $\mathrm{DI}$, and managing an interaction that involves one or more medications that should not be used by the patient. Therefore, the CMM service contributes to the deprescription of medications by proposing the suspension of those that are unnecessary, in order to avoid the patient experiencing adverse reactions (including those caused by DI) without any benefit in the use of the drug. ${ }^{11,21}$ 


\section{Conclusion}

Our study showed that it is fundamental to analyze the DI in a clinically contextualized manner. Also, professionals who intend to perform such analysis should distinguish the DI that can be monitored from those that are not monitorable. Finally, CMM service facilitates the management of $\mathrm{DI}$, since its decision-making method involucrate the deprescription of unnecessary drugs and monitoring of the effectiveness and safety parameters, allowing the individualized management of $\mathrm{DI}$ according to the patient's needs.

\section{Funding sources:}

This research did not receive funding for its completion.

\section{Collaborators}

HMS: Project conception, analysis and interpretation of data, article writing, critical review relevant. DRO.: Project conception, analysis and interpretation of data, critical review relevant and supervision. UMM.: Analysis and interpretation of data, critical review relevant. YAN.: Article writing and critical review relevant. AMR.: Article writing and critical review relevant AAS.: Article writing and critical review relevant. MGN.: Project conception, analysis and interpretation of data, article writing, critical review relevant and supervision.

\section{Acknowledgments:}

The authors would like to thank all clinical pharmacists at the CMM services from which the data were extracted and the patients who made this work possible.

\section{Conflict of interest's statement}

The authors declare that there are no conflicts of interest regarding this article.

\section{References}

1. Brumós LG. Interacciones Farmacológicas: Descripción Y Mecanismos Actitud Clínica Ante Las Interacciones Farmacológicas, $1^{\text {a }}$ edición. Madrid: Sociedad Española de Farmacia Hospitalaria: SEFH, 2013

2. Kennedy C, Brewer L, Williams D. Drug interactions. Medicine.2020; v. 48, n. 7, p. 450-455.

3. (EMA) European Medicines Agency. Guideline on the investigation of drug interactionsEuropean Medicine Agency. Available in: <http://www.cmaj.ca/lookup/doi/10.1503/ cmaj.150904>. Accessed on: $1^{\text {st }}$ May 2021.

4. Osório-de-Castro CGS. Interações Medicamentosas. In: Fuchs FD.; Wannmacher L (Eds.). Farmacologia Clínica e Terapêutica, $5^{\text {a }}$ edição. Rio de Janeiro: Editora Guanabara Koogan, 2017: 91-97.

5. Bibi Z. Retracted: Role of cytochrome P450 in drug interactions. Nutrition\&Metabolism. 2008; 5 (27) 1-10.

6. Baxter K. General considerations and an outline survey of some basic interaction mechanisms. In: Baxter K (Ed.). Stockley's Drug Interactions, 8 a edition. London: Pharmaceutical Press, 2008: 1-11.

7. Cornu P, Steurbaut S, Sostaric S, et al. Performance of a clinical decision support system and of clinical pharmacists in preventing drug-drug interactions on a geriatric ward. International Journal of Clinical Pharmacy. 2014; 36 (3): 519-525. DOI: 10.1007/s11096-014-9925-x.

8. Tilson $\mathrm{H}$, Hines EL, McEvoy $\mathrm{G}$, et al. Recommendations for selecting drug-drug interactions for clinical decision support. American Journal of Health-System Pharmacy. 2014; 73 (8): 576-585. DOI: 10.2146/ajhp150565.

9. Cipolle RJ, Strand LM, Morley PC. Pharmaceutical Care Practice: The patient-centered approach to medication management services, 3ªdition. New York: McGraw-Hill, 2012.

10. Ramalho-de-Oliveira, D. Atenção Farmacêutica: da filosofia ao gerenciamento da terapia medicamentosa, 1a edição. São Paulo: RCN Editora, 2011.

11. McClurg MR., Sorensen TD., Carroll J. The Patient Care Process for Delivering Comprehensive Medication Management (CMM): Optimizing Medication Use in Patient-Centered, Team-Based Care Settings.CMM in Primarcy Care Research TeamMinneapolisCMM in Primarcy Care Research Team. Available in: http://www.accp.com/cmm_care_process. Accessed on: $15^{\text {st }}$ Oct 2019.

12. Cipolle RJ, Strand LM, Morley PC. Drug Therapy Problems. In: Pharmaceutical care practice, $3^{a}$ edition. New York: McGraw-Hill, 2012:1-35.

13. WHO Collaborating Centre for Drug Statistics Methodology. Guidelines for ATC classification and DDD assignment. Available in: https://www.whocc.no/atc_ddd_index/. Accessed on: $08^{\text {st }}$ May 2021.

14. Vonbach P, Dubied A, Krahenbuhl S, et al. Evaluation of frequently used drug interaction screening programs. Pharmacy World \{\&\} Science. 2008; 30 (4):367-374. DOI: 10.1007/ s11096-008-9191-x.

15. Faroni AS, Souza CAS, Brito GC, et al. Possíveis interações medicamentosas entre usuários de uma unidade básica de saúde - UBS- do município de São Cristóvão-. Revista Saúde. com. 2015; 11(1): 10-19.

16. Pinto NBF, Vieira LB, Pereira FMV, et al. Interações medicamentosas em prescrições de idosos hipertensos: prevalência e significância clínica. Revista Enfermagem UERJ. 2014; 22 (6):735-741.

17. Masnoon N, Shakib S, Kalisch-Ellett, et al. What is polypharmacy? A systematic review of definitions. BMC Geriatrics. 2017:17(1); 1-10. DOI: 10.1186/s12877-017-0621-2.

18. Neto Pro, Nobili A, Lyra-Jr DP, et al. Incidence and predictors of adverse drug reactions caused by drug-drug interactions in elderly outpatients: A prospective cohort study. Journal of Pharmacy and Pharmaceutical Sciences. 2012; 15 (2): 332343. DOI: $10.18433 / j 3 c c 86$

19. Santos BD, Nascimento MMGD, de Oliveira GCB, et al. Clinical Impact of a Comprehensive Medication Management Service in Primary Health Care. J Pharm Pract. 2019; 20 (10) 1-7. DOI: 10.1177/0897190019866309. 
20. Davies EA, O'Mahony MS. Adverse drug reactions in special populations: the elderly. Br J Clin Pharmacol. 2015; 80(4):796807. DOI: 10.1111/bcp.12596.

21. Santos TO, Nascimento MMG, Nascimento YA, et al. Drug interactions among older adults followed up in a comprehensive medication management service at Primary Care. Einstein.2019;17(4):1-9. DOI: 10.31744/einstein_journal/2019A04725.

22. Liao HL, Chen JT, Ma TC, et al. Analysis of drug-drug interactions (DDIs) in nursing homes in Central Taiwan. Archives of Gerontology and Geriatrics. 2008; 47 (1): 99-107. DOI: 10.1016/j.archger.2007.06.007

23. Hoffmann W, Van-den-Berg N, Thyrian JR, et al. Frequency and determinants of potential drug-drug interactions in an elderly population receiving regular home visits by GPS - results of the home medication review in the AGnES-studies. Pharmacoepidemiology and Drug Safety. 2011; 20 (12): 1311-1318. DOI: 10.1002/pds.2224.

24. Dumbreck S, Flynn A, Nairn M, et al. Drug-disease and drug-drug interactions: systematic examination of recommendations in 12 UK national clinical guidelines. BMJ (Clinical research ed.). 2015; v. 350

25. Roumie CL, Min JY, Greevy RA, et al. Risk of hypoglycemia following intensification of metformin treatment with insulin versus sulfonylurea. Canadian Medical Association Journal. 2016; 188(6):104-E112. DOI: DOI: 10.1503/cmaj.150904.

26. Iniesta-Navalón C, Gascón-Cánovas JJ, Gama ZAS, et al. Potential and clinical relevant drug-drug interactions among elderly from nursing homes: a multicentre study in Murcia , Spain. Ciência \& Saúde Coletiva. 2019; 24(5):1895-1902. DOI: 10.1590/1413-81232018245.16032017.

27. Oka Y, Okamoto K, Kawashita N, Shirakuni Y, et al. Meta-analysis of the risk of upper gastrointestinal hemorrhage with combination therapy of selective serotonin reuptake inhibitors and non-steroidal anti-inflammatory drugs. Biological and Pharmaceutical Bulletin. 2014;37(6): 947-953. DOI: 10.1248/ bpb.b13-00885

28. Shin JY, Park MJ, Lee SH, et al. Risk of intracranial haemorrhage in antidepressant users with concurrent use of non-steroidal anti-inflammatory drugs: nationwide propensity score matched study. BMJ. 2015; 351:3517. DOI: 10.1136/bmj. h3517.

29. HO, KY, Cardosa MS, Chaiamnuay S, et al. Practice Advisory on the Appropriate Use of NSAIDs in Primary Care. Journal of Pain Research. 2020; 13:1925-1939. DOI: 10.2147/JPR. S247781.

30. Krauss $\mathrm{E}$, Croin MA, Dengler $\mathrm{N}$, et al. Interaction Between Low-Dose Aspirin and Nonsteroidal Anti-Inflammatory Drugs Can Compromise Aspirin' s Efficacy in Preventing Venous Thrombosis Following Total Joint Arthroplasty. Clinical and Applied Thrombosis/Hemostasis. 2020; 26: 0-4. DOI: DOI: 10.1177/1076029620920373

31. Macdonald TM.; Wei L. Effect of ibuprofen on cardioprotective effect of aspirin Migration of human keratinocytes in plasma and serum and wound For personal use. Only reproduce with permission from The Lancet Publishing Group. The Lancet.
2003; 361: 573-574. DOI: 10.1016/s0140-6736(03)12509-3.

32. Moore N, Pollack C, Butkerait, P. Adverse drug reactions and drug - drug interactions with over-the-counter NSAIDs. Therapeutics and Clinical Risk Management. 2015; 11:10611075. DOI: 10.2147/TCRM.S79135. 